\title{
Dilution of Cigarette Smoke through Ventilation of Filters*
}

\author{
by William A. Selke \\ Research Department, Schweitzer Division, Kimberly-Clark Corporation, \\ Lee, Massachusetts, U.S.A.
}

\section{INTRODUCTION}

There is increasing interest in measuring and predicting the degree of dilution of cigarette smoke effected by ventilating the filter $(1,2)$. It is recognized that this dilution depends upon an interrelationship of a number of factors, including not only the resistance to the influx of air presented by the tipping and filter plug wrap paper, but also on the location of the vents in the filter tip and on the pressure drop characteristics of the lighted tobacco rod, itself.

This paper deals with a simple, graphical representation which can account for the influences of these variables.

\section{GENERAL PRINCIPLE}

During the puff in the standard smoking regime, the flow from the end of the cigarette is 1050 milliliters per minute, this being the sum of the flow entering the filter from the tobacco column and the flow entering the vents. Air is thus flowing through two channels, in parallel, the entrance to each being at atmospheric pressure and the flows converging at a point where the vacuum level is necessarily the same. This is shown schematically in Fig. 1. The pressure at this point of junction, inside the filter medium directly inside the ventilation band of the tipping, is designated $P_{1}$. The rod, on one hand, and the vents, on the other, will contribute to that total flow of $1050 \mathrm{ml}$ per minute according to the flow/pressure drop relationship of each. In order to predict these relative contributions, it is necessary to know the following:

$$
\begin{aligned}
& F_{\text {rod }}=\Phi_{1}\left(\Delta P_{i}\right), \\
& F_{\text {vents }}=\Phi_{2}\left(\Delta P_{i}\right),
\end{aligned}
$$

where

$\mathrm{F} \quad=$ air flow,

$\Delta \mathrm{P} \quad=$ pressure differential causing flow through the rod or through the vents,

$\Phi_{1}, \Phi_{2}=$ function characteristic of specific construction.

It should be noted that $\Phi_{1}\left(\Delta P_{i}\right)$ represents the draw

\footnotetext{
* Presented, in part, at the Coresta Technology Study Group meeting held in Munich, Germany, in September 1977.
}

Figure 1. Schematic representation of gas flows.

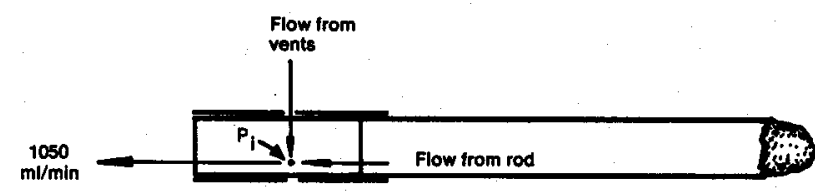

resistance characteristic of the lighted rod together with that of the portion of the filter upstream of the vents. The resistance to draw of the filter downstream of the vents influences the resistance to draw of the entire cigarette, but has no influence on the degree of ventilation.

These functions of flow viersus pressure drop are plotted, each on a scale of flow from 0 to $1050 \mathrm{ml}$ per minute, with the flow through the vents being plotted positively, in the conventional fashion, and that through the rod being plotted in reverse, as is shown in Fig. 2.

Since, at the point at which these two curves cross the sum of these two flows equals $1050 \mathrm{ml}$ per minute, the point of intersection represents the pressure level, $P_{i}$, obtaining inside the filter when the flow from the cigarette is at that standard total flow. The portion of flow which enters through the vents and that through rod is indicated by the ordinate values at that crossing.

\section{Flow and Pressure Relationship for the Rod}

The value of $\Delta P_{\text {rod }}$ employed is the sum of the pressure drop of the lighted tobacco column and that of the appropriate portion of the filter.

The resistance of the lit cigarette is significantly higher

Figure 2. Method of plotting flows and pressure drops.

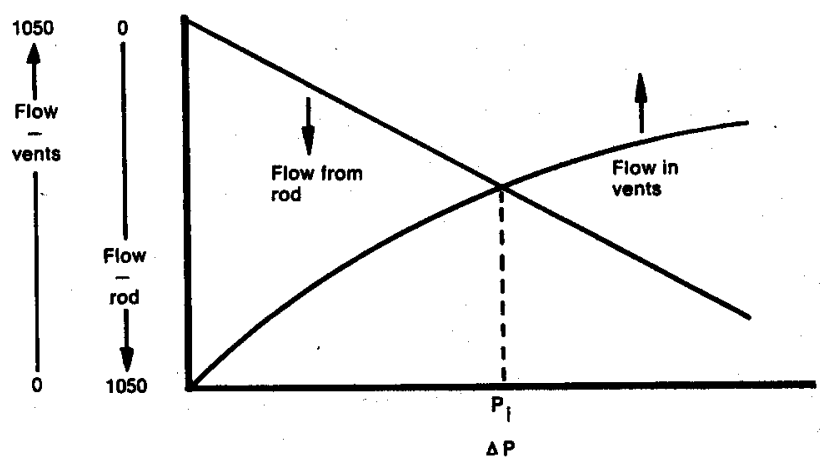


than that of an unlit tobacco column $(3,4,5)$ and the dilution of a lit cigarette is therefore significantly greater than that of one which is unlit.

Unlike a cellulose acetate filter, the lighted tobacco rod does not always represent an "ohmic" or constant resistance to air flow. A most direct method of determining the pressure drop characteristics of the lit cigarette is to connect a well damped manometer to a smoking madine in which the puff volume can be adjusted while smoking a non-filter rod. Alternatively, using empirical measurements of the coal resistance as a function of air flow, incremental calculations can be made, taking into consideration the influences of the dilution air through that section of the rod upstream of the tipping paper. This is particularly appropriate for consideration of the effect of change in permeability of the cigarette paper on $F_{r o d}=\Phi_{1}(\Delta P)$.

The resistance to draw of the appropriate portion of the filter can be added to that of the tobacco rod by calculation. This is particularly useful when assessing the influence of change of vent location. Alternatively, filter cigarettes can be cut through the filter at the midpoint of the vents and the measurements described above made on the lighted cigarettes.

The pressure-flow characteristic of the vents depends on the permeability of the tipping (which is probably perforated, but could be inherently porous), the air resistance of the plug wrap, and the tightness of the wrap of the tipping on the plug wrap.

The effective area of plug wrap paper through which air passes is somewhat greater than that of the perforations of the tipping external to it because there is always a certain amount of lateral air flow in the unglued area between the tipping and plug wrap papers. The magnitude of this lateral flow is governed by the roughness of the plug wrap paper and the tightness with which it is pressed by the tipping paper. Mathews and Selke (6) found in measurements in several commercial cigarettes that this lateral distribution was approximately equivalent to the extension outward in each direction of about 0.1 millimeter. This represents a significant augmentation of the area of the perforation when the holes are quite fine and a more modest increase when large perforations are employed.

For approximate predictions, the value of $F_{\mathrm{vents}}=$ $\Phi_{2}\left(\Delta P_{i}\right)$ can be calculated from permeability measurements on the tipping and plug wrap papers, with the effective area of the latter adjusted for lateral flow.

If specimens of the ventilated filter tips are available, measurement can be made directly. This can be done by sealing one end of the tip and then determining entering air flow as a function of vacuum level at the outlet. The vents should then be sealed with pressuresensitive tape, the tip cut off at the midpoint of the perforation and the measurement resistance to draw determined. Subtraction of this latter pressure as a function of flow results in the desired value of $F_{\text {vents }}=$ $\Phi_{\mathcal{g}}\left(\Delta P_{i}\right)$.

\section{EXPERIMENTAL}

\section{Cigarettes Tested}

For the purpose of verifying the graphical method, two types of cigarettes were tested. Cigarette $A$ was $70 \mathrm{~mm}$ in overall length and was wrapped with cigarette paper at a permeability of $54 \mathrm{~cm} / \mathrm{min}$ measured at one cbar. The tipping paper had two rows of laser perforation. Cigarette $B$ was $85 \mathrm{~mm}$ long and was wrapped with paper with a permeability of 30 in the Coresta units (7). Its tipping paper had a single row of mechanical perforation.

Measurements were made on both types of cigarettes of the dilution during the first puff and during a later puff, these being when $19 \mathrm{~mm}$ of tobacco rod remained unburned in the case of cigarette $A$ and $24 \mathrm{~mm}$ in the case of cigarette $B$.

\section{Pressure Drop and Dilution Measurements}

The flow resistance functions $\Phi_{1}$ and $\Phi_{2}$ were measured directly on the tobacco rods and on the ventilation systems of each type of cigarette. The values of $\Phi_{1}\left(\Delta P_{i}\right)$ were obtained by attaching a capillary to the entrance end of the rod, simulating the coal resistance.

The dilution flows were determined by direct steadystate measurements on the assembled cigarettes. The resistance of the lighted coal can by no means be neglected, but for simplicity, the resistance of the coal was again simulated. To the entrance end of the cigarette was connected a glass capillary the dimension previously found to approximate the coal resistance.

The dilution flow was measured with a variable area orifice meter in the line feeding a compartment around the vents. The pressure drop in that meter was balanced by adjusting the air inlet pressure to bring the pressure inside that compartment to atmospheric pressure using an open manometer.

\section{RESULTS AND DISCUSSION}

In Fig. 3 are shown the measurements on cigarette $A$ of the pressure drop functions $\Phi_{2}\left(\Delta P_{i}\right)$ and the values of the function $\Phi_{1}\left(\Delta P_{i}\right)$ for the first puff and for the intermediate puff. Fig. 4 presents similar measurements on cigarette $B$.

The dilution values predicted from the intersection of those curves and the measured values are given in Table 1.

It is interesting to note that in both cases the dilution through the filter is diminished only slightly as the length of the cigarette decreases. If cigarettes are wrapped with paper of very low permeability, the graphical analysis shows a decrease in filter dilution with increasing puff number, while with paper of extremely high permeability, the dilution at the filter increases. However, in the latter case the total dilution, including that through the wrapper, will generally decrease. 
Figure 3. Graphical calculation of dilution - cigarette A.

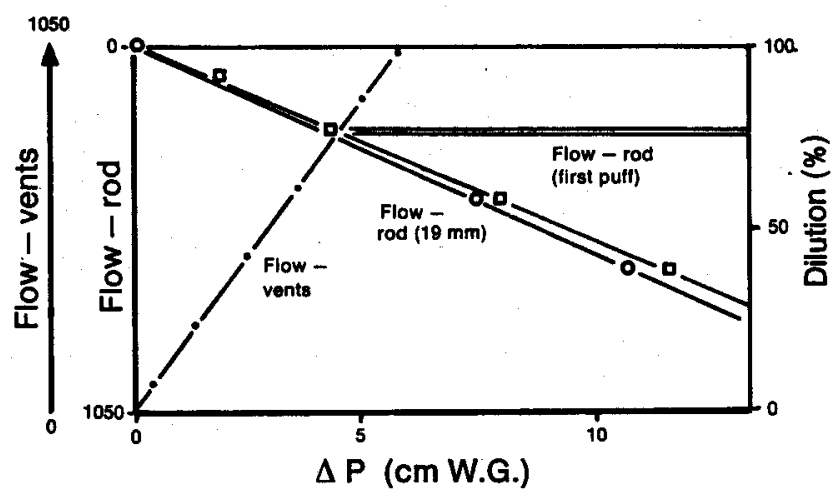

Figure 4. Graphical calculation of dilution - clgarette B.

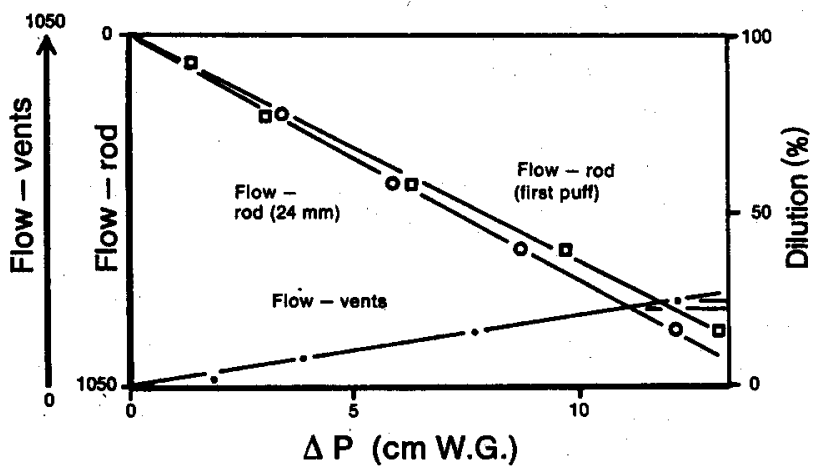

If all remained unchanged except the location of the perforations, the slope of the line representing $\Phi_{1}\left(\Delta P_{i}\right)$ would be altered by the change in the fraction of the filter to be included with the burning tobacco rod. Moving the holes closer to the mouth end would flatten the curve and would increase the dilution. The effect of other variations can be predicted analogously.

\section{CONCLUSION}

The technique which is presented displays the effect of varying the parameters of cigarette design on the dilution through a ventilating filter. These variables include those affecting the pressure drop of the tobacco rod as well as variation in the nature and location of the ventilation in the filter.

It is proposed that this method can have utility both in predicting the changes in dilution resulting from change in the design of the cigarette and in predicting the variability of the dilution caused by variability in the components of the cigarette, such as the perforated tipping paper and the porous plug wrap.

\section{SUMMARY}

A graphical method is presented showing the interrelationship of the air flow resistance of the cigarette, itself, and that of the ventilation in the filter tips in determining the dilution produced by that ventilation.

The method was checked by direct, steady-state measurements of dilution of unlit cigarettes to which a resistance was added simulating the resistance of the burning coal.
Table 1. Predicted and observed values of dilution.

\begin{tabular}{|c|c|c|c|}
\hline & & \multicolumn{2}{|c|}{ Dilution } \\
\hline & & $\begin{array}{l}\text { calculated } \\
\text { from graph }\end{array}$ & observed \\
\hline Cigarette A & $\begin{array}{l}\text { 1st puff } \\
\text { later puff }\end{array}$ & $\begin{array}{l}76 \% \\
75 \%\end{array}$ & $\begin{array}{l}78 \% \\
77 \%\end{array}$ \\
\hline Cigarette B & $\begin{array}{l}\text { 1st puff } \\
\text { later puff }\end{array}$ & $\begin{array}{l}23 \% \\
22 \%\end{array}$ & $\begin{array}{l}18 \% \\
17 \%\end{array}$ \\
\hline
\end{tabular}

\section{ZUSAMMENFASSUNG}

Es wird eine graphische Methode beschrieben, die den Zusammenhang herstellt zwischen dem Zugwiderstand der Cigarette einerseits und der resultierenden Verdünnung des Rauches aufgrund von Ventilation des Einzelfilters andererseits. Geprüft wurde die Methode durch direkte Messung der Verdünnung bei stationären Strömungen in nicht brennenden Cigaretten, wobei durch Hinzufügen eines Strömungswiderstandes der Glutkegel simuliert wurde.

\section{RESUME}

Une méthode graphique est présentee, montrant l'interrelation de la résistance au flux d'air de la cigarette d'une part, et la dilution de la fumée résultant de la ventilation du bout filtre d'autre part.

Cette méthode a été vérifiée par mesures directes, en régime stationnaire, de la dilution de cigarettes non allumées auxquelles on a ajouté une résistance simulant celle de la braise.

\section{REFERENCES}

1. Keith, C. H.: Paper presented at the joint meeting of Coresta Smoke and Technology Study Groups, held in Munich, Germany, in September 1977.

2. Reynolds, J. H., and J. P. Wheeler: Tobacco Science XXI (1977) 85.

3. Jarman, R. T.: Paper presented at the Fourteenth Tobacco Chemists' Research Conference, WinstonSalem, N. C., U.S.A., October 1960.

4. Lorenz, H.-W., and F. Seehofer: Beitr. Tabakforsch. 6 (1971) 1 .

5. Baker, R. R.: Beitr. Tabakforsch. 8 (1975) 124.

6. Selke, W. A., and J. H. Mathews: Paper presented at Coresta Technology Study Group meeting held in Munich, Germany, in September 1977; Beitr. Tabakforsch. 9 (1978) 193.

7. Coresta Recommended Method No. 3: Determination of the air permeability of cigarette paper; Coresta Information Bulletin 1975-3/4, 38-41.

\section{Adenowledgement}

The author wishes to thank his colleague Dr. Donald Duroder for bis assistance.

Author's address:

Research Department, Schweitzer Division, KimberlyClark Corporation, Lee, Massachusetts, 01238, U.S.A. 